\title{
The effect of attention and interpretation therapy on psychological resilience, cancer-related fatigue, and negative emotions of patients after colon cancer surgery
}

\author{
Chunyan Lin, Yu'e Diao, Zhixia Dong, Jie Song, Chuanqing Bao \\ Department of Gastroenterology, the Affiliated Hospital of Jiangnan University, Wuxi, China \\ Contributions: (I) Conception and design: C Lin, Y Diao, Z Dong; (II) Administrative support: C Bao; (III) Provision of study materials or patients: C \\ Lin, Y Diao, J Song; (IV) Collection and assembly of data: C Lin, Z Dong, J Song, C Bao; (V) Data analysis and interpretation: C Lin, Y Diao; (VI) \\ Manuscript writing: All authors; (VII) Final approval of manuscript: All authors. \\ Correspondence to: Chuanqing Bao. Department of Gastroenterology, Affiliated Hospital of Jiangnan University, Wuxi 214041, China. \\ Email: mollylcy@126.com.
}

Background: Colon cancer is the most common malignant tumor of the gastrointestinal tract. This cancer and the related treatments bring a raft of lasting physiological and psychological impacts to patients. This study explored the effects of attention and interpretation therapy (AIT) on improving psychological resilience, cancer-related fatigue (CRF), and negative emotions in patients after colon cancer surgery.

Methods: Patients who had undergone colon cancer surgery in the Affiliated Hospital of Jiangnan University were selected and randomly allocated into an experimental group and a control group, each with 100 cases. Patients in the control group received routine intervention measures, while the experimental group received an extra 10 weeks of AIT. Before and after 10 weeks of intervention, the effects of intervention were evaluated using the Connor-Davidson Resilience Scale (CD-RISC), Self-Rating Anxiety Scale (SAS), Selfrating Depression Scale (SDS) and the Revised Piper Fatigue Scale (PFS-R).

Results: Before the intervention, there was no statistical difference between the scores of psychological resilience, CRF, and negative emotions between the two groups $(\mathrm{P}>0.05)$. We compared the scores before and after the 10 weeks of intervention and found that the scores of psychological resilience of the experimental group were higher than before, and the scores of CRF and negative emotion were lower than before. After the intervention, the psychological resilience score of the experimental group was higher than that of the control group, the CRF and negative emotions scores were lower than those of the control group, and the differences were statistically significant $(\mathrm{P}<0.05)$.

Conclusions: AIT can effectively strengthen the psychological resilience of patients after colon cancer surgery to a certain extent, reduce anxiety and depression, reduce the degree of CRF, and thus improve the patients' quality of life postoperatively.

Keywords: Attention therapy; interpretation therapy; colon cancer; psychological resilience; cancer-related fatigue (CRF); negative emotions

Submitted Jun 12, 2020. Accepted for publication Aug 21, 2020.

doi: 10.21037/apm-20-1370

View this article at: http://dx.doi.org/10.21037/apm-20-1370 


\section{Introduction}

Colorectal cancer is currently one of the most common malignant tumors of the digestive tract in the world. Relevant literature shows that among the total mortality and morbidity of all cancers in Western countries, the mortality and morbidity of colorectal cancer ranks second. The epidemiological survey of colorectal cancer in my country has shown that the incidence of colorectal cancer is on the rise, and its incidence and mortality are ranked 4th and 5th in the total incidence and mortality of cancer in China. With the improvement of living standards and the continuous changes in environment and lifestyle, the incidence of colon cancer has risen steadily (1). At present, the treatment mode of colon cancer is no longer the single surgical resection of the past. Comprehensive treatment based on surgery is an important treatment principle for colorectal cancer, including surgery, radiotherapy, chemotherapy, immunotherapy, targeted therapy, traditional Chinese medicine treatment, nursing participation and other methods. Multidisciplinary comprehensive treatment based on surgical resection is an important treatment principle for colorectal cancer today (2). After colorectal cancer surgery, patients often have complications such as intestinal dysfunction and abdominal adhesions, especially for patients with intestinal stoma. The surgery not only brings physical discomfort to the patient, but also causes great psychological pressure, leading to their social psychology. Changes in state and psychological activities have reduced the quality of life of some patients. In the past, the quality of a certain surgical method mainly relied on the survival rate of patients after surgery, tumor recurrence rate, the number of lymph nodes removed, and the scope of tumor intestinal resection, while less consideration was given to the happiness or pain of the operation itself. Studies have reported (3-5) that about one-third of cancer patients experience severe anxiety and depression. As a key component of positive psychology (6), psychological resilience is considered to be the psychological and behavioral response of the subject to the changed environment (7). While psychological resilience is a popular field of psychological research, few studies have focused on the psychological resilience of colon cancer patients in China. Cancer-related fatigue (CRF) is a painful, persistent, cancer- or cancer treatment-related subjective feeling of exhaustion disproportionate to activity levels, which is often accompanied by dysfunction. CRF incidence is very common and lasting in cancer patients, and seriously affects physical and mental health (8-10). The implementation of effective interventions to bolster psychological resilience of cancer patients, thereby alleviating CRF and reducing negative emotions, is vitally important to improve the quality of life of patients after surgery. Attention and interpretation therapy (AIT), as proposed by Loprinzi et al. (11), is a systematic method based on stress management and psychological resilience training. The goal of AIT is two-pronged $(4,12)$ : the first aim is to divert the patient's attention away from the threat posed by the cancer, train the patients' focus on new prospects, and cultivate a positive, optimistic, and grateful attitude towards life. The second is to help the patient be aware of and avoid negative emotions and to increase their psychological flexibility, thus minimizing stress, enhancing emotional management, and fostering their ability to physically and mentally adapt. Studies have shown that AIT can effectively improve the psychological elasticity of patients with gastrointestinal tumors to a certain extent and reduce anxiety and depression (13). The purpose of this study was to explore the effects of AIT on psychological resilience, CRF, and the negative emotions of patients after colon cancer surgery in order to generate a base of evidence for further promotion and application of this model in the future. We present the following article in accordance with the CONSORT reporting checklist (available at http://dx.doi.org/10.21037/ apm-20-1370).

\section{Methods}

\section{Subjects}

Using the convenience sampling method, 200 colon cancer patients admitted between March 10, 2018 and December 25, 2019 to the Affiliated Hospital of Jiangnan University were selected as the research sample and were placed into an experimental or control group using a random number table. Each group comprised 100 cases. The inclusion criteria were as follows: (I) age $\geq 18$ years old; (II) colon cancer diagnosis confirmed through pathological specimens; (III) treated with surgery; (IV) cognizance of own condition with the ability to express personal ideas; (V) not participating in other studies or psychological interventions that could affect the results of this study. The exclusion criteria were as follows: (I) other malignant tumors; (II) impaired function of vital organs such as the heart, liver, or kidney; (III) comorbid severe mental illness. This study was conducted in accordance with the ethical principles of 
the Declaration of Helsinki (as revised in 2013), and was approved by the ethics committee of our hospital [(2017) KY098]. The study obtained the signed informed consent of all patients.

\section{Interventions}

The routine care of the patients in the control group mainly included dietary advice, infection prevention, and oral care guidance, along with monitoring of signs of bone marrow suppression, giving medication according to the doctor's instructions if needed, and providing diseaserelated education after surgery. On the seventh day postsurgery, patients began progressive muscle relaxation training, which was performed daily for $30 \mathrm{~min} /$ time for 10 weeks. During the period of hospitalization, the completion of the training was supervised by the responsible nurse; after being discharged, the patient was supervised by telephone follow-up.

On the basis of routine nursing, the experimental group set the intervention plan according to the theoretical basis of AIT. The experimental group was divided into 10 groups with 10 patients in each group. Before intervention, each group established a personal file based on the patient's case information, existing problems, and emotional state. All patients underwent the first intervention on the seventh day after the operation. As stipulated by the evaluation indicators of AIT, each patient participated in a 10-week stress management and psychological resilience training course. The specific intervention content is shown in Table 1.

\section{Investigation method \\ General information questionnaire}

The researchers compiled a general demographic information questionnaire, including gender, age, marital status, education level, payment method, and tumor-nodemetastasis (TNM) staging.

\section{Psychological resilience assessment scale}

The patients' psychological resilience was assessed using the Connor-Davidson Resilience Scale (Connor-Davidson Resilience Scale, CD-RISC) (14). The scale includes a total of 25 items distributed across the 3 following dimensions: self-confidence (13 items), tenacity ( 8 items), and optimism (4 items). The items use the Likert 5-level scoring method, with 0 being "not true at all" and 4 being "true nearly all of the time". Scores range from 0 to 100 , with a higher score indicating better psychological resilience. A Chinese version of the scale was revised by Wu et al. in 2017, which yielded a Cronbach $\alpha$ coefficient of 0.91 (15).

\section{CRF assessment scale}

Patients with CRF were evaluated using the Revised Piper Fatigue Scale (PFS-R) (16). The scale is composed of 22 items categorized into the 4 following dimensions: behavioral severity (6 items), affective meaning (5 items), somatic sensation (5 items), and cognition/mood (6 items). Each item was scored on a visual analog scale from 0 to 10 , with 0 indicating no fatigue and 10 indicating extreme fatigue. The score of each item was divided by the number of items to obtain the scale score. Higher scores were an indication of patients experiencing more severe fatigue. The testretest reliability of the scale was 0.980 , the total Cronbach's $\alpha$ coefficient of the scale was 0.914 , and the Cronbach's $\alpha$ coefficient of each dimension was 0.891-0.932 (17).

\section{Negative affect scale}

The Self-rating Anxiety Scale (SAS) and the Self-rating Depression Scale (SDS) were used to assess the anxiety and depression levels of the two groups. The SAS and SDS both contain 20 items, and adopt the following 4-level scoring method: "none/insignificant", "mild/some of the time in frequency", "moderate/a good part of the time in frequency", "severe/most or all of the time in frequency"; these levels are scored $1-4$ respectively. An SAS score $\geq 50$ points indicates anxiety, an SDS score $\geq 53$ points indicates depression, with even higher scores indicating a greater severity of anxiety and depression $(18,19)$.

\section{Survey methods}

Surveys were conducted jointly by investigators and researchers who had undergone unified training. Everyone involved in administering the surveys used the same instructions to distribute questionnaires to those who met participation criteria. If the patient could not fill out the questionnaire themselves for some reason, the investigator read each question to the patient in a neutral and nondirective manner. After ensuring the patient had understood the question, the investigator helped them complete the questionnaire. The questionnaire was distributed and completed in one sitting.

\section{Statistical analysis}

SPSS 22.0 software was used for statistical analysis of all data. The measurement data are expressed as mean \pm 
Table 1 The intervention content of AIT

\begin{tabular}{|c|c|c|c|}
\hline $\begin{array}{l}\text { Time } \\
\text { (week) }\end{array}$ & Training method & Training content & Quality control methods \\
\hline 1 & Intensive teaching & $\begin{array}{l}\text { Explain to the patient the theoretical knowledge } \\
\text { and intervention process of AIT }\end{array}$ & $\begin{array}{l}\text { After the lecture, ask patients questions to } \\
\text { consolidate what they have learned }\end{array}$ \\
\hline 2 & $\begin{array}{l}\text { Transcendental } \\
\text { meditation }\end{array}$ & $\begin{array}{l}\text { Introduce the method of transcendental meditation } \\
\text { training, and emphasize the three elements of } \\
\text { meditation, with closed eyes and contemplation }\end{array}$ & $\begin{array}{l}\text { Choose a quiet and ventilated training environment } \\
\text { and control the training time }\end{array}$ \\
\hline 4 & $\begin{array}{l}\text { Cultivating } \\
\text { appreciation }\end{array}$ & $\begin{array}{l}\text { Instruct patients to be grateful to the family } \\
\text { members, friends, and medical staff who help them }\end{array}$ & $\begin{array}{l}\text { After training, encourages patients to share their } \\
\text { gratitude and experience }\end{array}$ \\
\hline 7 & $\begin{array}{l}\text { Acceptance and } \\
\text { commitment therapy }\end{array}$ & $\begin{array}{l}\text { Reduce patient's subjective judgment, help them } \\
\text { accept the disease, and guide patients to actively } \\
\text { cope with life and establish productive values }\end{array}$ & $\begin{array}{l}\text { Pay attention to psychological changes during } \\
\text { training and control training time }\end{array}$ \\
\hline 8 & $\begin{array}{l}\text { Life-review therapy } \\
\text { (LR) }\end{array}$ & $\begin{array}{l}\text { Encourage and guide patients to recall the most } \\
\text { beautiful things in life and recall positive life } \\
\text { experiences }\end{array}$ & $\begin{array}{l}\text { Check the content of growth anecdotes and } \\
\text { distribute small gifts }\end{array}$ \\
\hline
\end{tabular}

AIT, attention and interpretation therapy.

standard deviation. Two independent samples $t$-test were used for comparison between groups, and a paired $t$-test was used for comparison within groups. Count data are expressed as number of cases and rate (\%), and the ChiSquare $\left(\chi^{2}\right)$ test was used for comparison between groups. Statistical significance was set at $\mathrm{P}<0.05$.

\section{Results}

\section{Comparison of general patient information in the two groups}

This study comprised 200 post-surgery colon cancer patients, with 100 patients allocated to each of the experimental group and control group. The control group participants' general information is described below: gender: 68 males (68\%) and 32 females (32\%); age: 18 (18\%) under 50 years, $30(30 \%)$ between 50 and 60 years, $42(42 \%)$ between 60 and 70 years, and $10(10 \%)$ over 70 years; education level: 64 (64\%) high school and below, and $36(36 \%)$ junior college and above; marital status: 80 $(80 \%)$ married, 7 (7\%) unmarried, 13 (13\%) divorced or widowed; medical payment methods: 48 (48\%) medical insurance, 44 (44\%) new rural cooperative medical system (NCMS), and 8 (8\%) self-funded; TNM staging: 58 (58\%) 
Table 2 Comparison of general information between the two groups

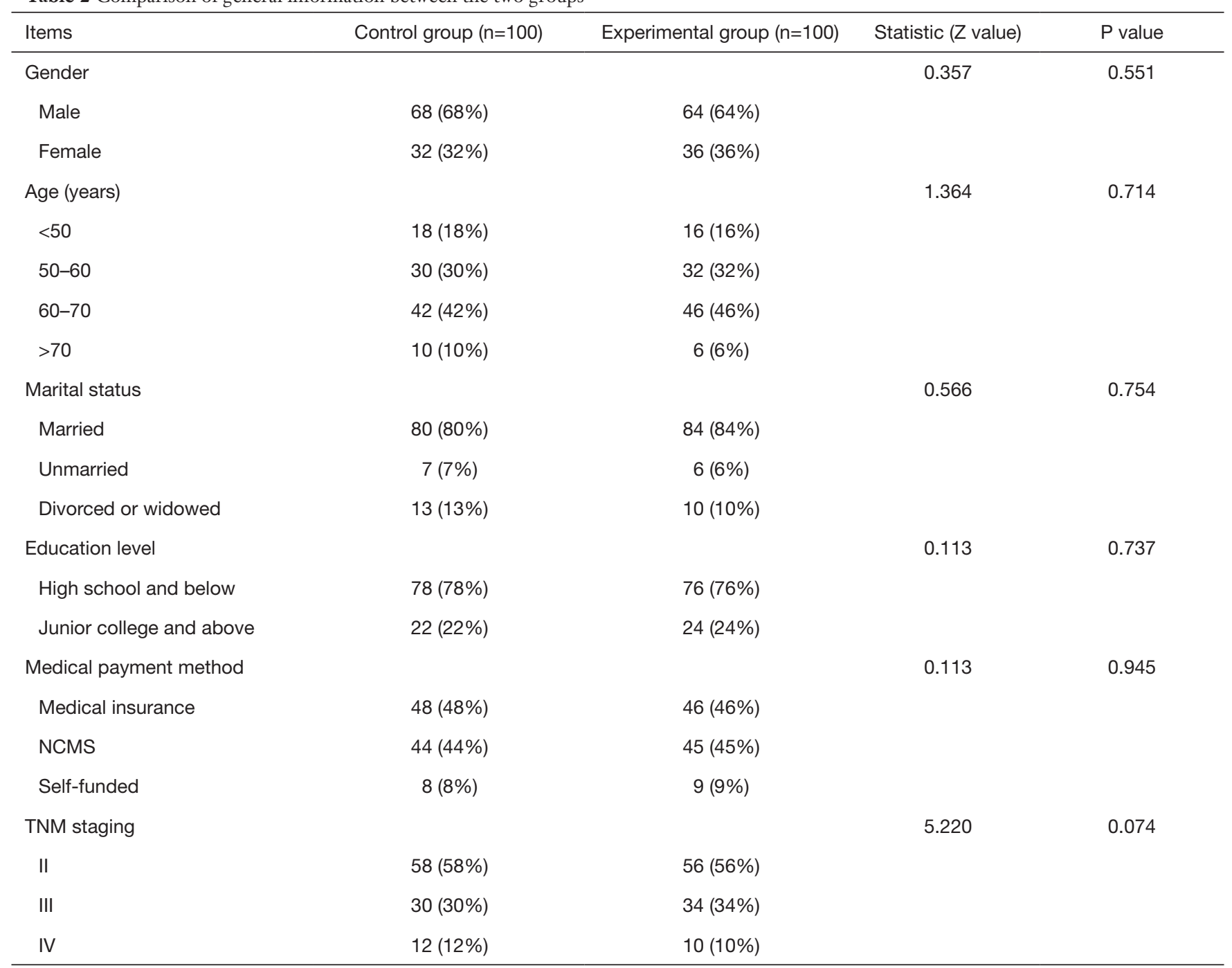

NCMS, new rural cooperative medical system.

stage II, 30 (30\%) stage III, and 12 (12\%) stage IV.

The experimental group participants' general information is described below. Gender: 64 males (64\%) and 36 females (36\%); age: $16(16 \%)$ under 50 years, 32 (32\%) between 50 and 60 years, $46(46 \%)$ between 60 and 70 years , and 6 (6\%) over 70 years; education level: 76 (76\%) high school and below and 24 (24\%) junior college and above; marital status: 84 (84\%) married, 6 (6\%) unmarried, and $10(10 \%)$ divorced or widowed; medical payment methods: 46 (46\%) medical insurance, 45 (45\%) NCMS , and 9 (9\%) selffunded; TNM staging: 56 (56\%) stage II, 34 (34\%) stage III, and $10(10 \%)$ stage IV. The differences in gender, age, education level, marital status, medical payment method, and TNM staging of patients between the two groups were not statistically significant $(\mathrm{P}>0.05)$, and were comparable (see Table 2).

\section{Comparison of each dimension score and total score of the psychological resilience scale between the two patient groups before and after intervention}

Before the intervention, the total psychological resilience score, tenacity dimension, self-confidence dimension, and optimism dimension of the experimental group $(55.42 \pm 3.51$ points, $27.73 \pm 3.59$ points, $18.07 \pm 3.00$ points, $55.52 \pm 3.7$ points, $9.73 \pm 4.51$ points, respectively) were not statistically 
Table 3 Comparison of psychological resilience scores between the two groups of patients before and after intervention $(\bar{x} \pm$ SD, \%)

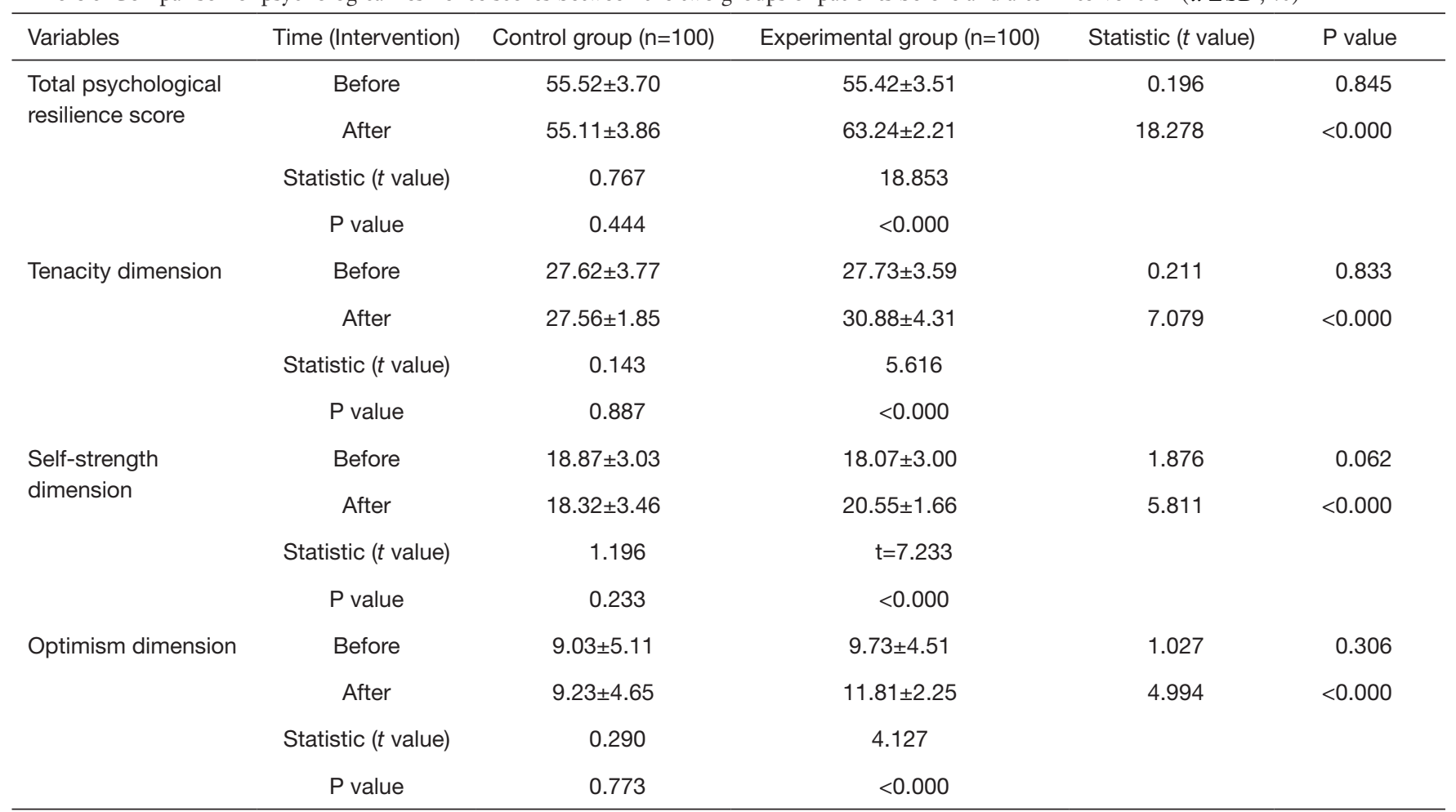

different from those of the control group $(55.52 \pm 3.70$ points, $27.62 \pm 3.77$ points, $18.87 \pm 3.03$ points, $9.03 \pm 5.11$ points, respectively) $(\mathrm{P}>0.05)$. After the intervention, the total psychological resilience score and the scores of each dimension of the experimental group $(63.24 \pm 2.21$ points $30.88 \pm 4.31$ points, $20.55 \pm 1.66$ points, $11.81 \pm 2.25$ points, respectively, as above) were all significantly higher than those before the intervention, and the difference was statistically significant $(\mathrm{P}<0.05)$. The score of each dimension of the control group was not statistically significant when compared to before the intervention $(\mathrm{P}>0.05)$ (see Table 3).

\section{Comparison of CRF between the two groups before and after intervention}

Before intervention, the experimental group's dimensions in behavioral severity, affective meaning, somatic sensation, and cognition/mood $(5.88 \pm 1.21$ points, $6.06 \pm 1.14$ points, $6.56 \pm 1.08$ points, $6.49 \pm 1.18$ points, respectively) were not statistically different from those of the control group $(5.56 \pm 1.20$ points, $6.04 \pm 1.05$ points, $6.81 \pm 1.13$ points, $6.78 \pm 1.31$ points, respectively) $(\mathrm{P}>0.05)$. After the intervention, the scores of each dimension of the experimental group $(4.04 \pm 1.05$ points, $4.01 \pm 1.15$ points, $4.14 \pm 1.54$ points, $5.21 \pm 1.12$ points, respectively, as above) were significantly lower than those before the intervention, and the differences were statistically significant $(\mathrm{P}<0.05)$, while the scores of all dimensions in the control group were not significantly different from those before intervention $(\mathrm{P}>0.05)$ (see Table 4).

\section{Comparison of negative affect scale scores between the two groups of patients before and after intervention}

Before the intervention, the SAS and SDS scores of the experimental vs. control groups $(56.42 \pm 3.98$ points $v s$. $56.14 \pm 2.97$ points, $55.71 \pm 4.11$ points $v s .56 .55 \pm 4.01$ points) were compared, and there was no statistically significant difference $(\mathrm{P}>0.05)$. After the intervention, the scores of SAS and SDS in the experimental group $(44.42 \pm 3.64$ points, $43.95 \pm 4.14$ points, respectively) were significantly lower than those before the intervention, and the differences were statistically significant $(\mathrm{P}<0.05)$, while the control group's SAS and SDS scores $(56.55 \pm 4.21$ points, $55.12 \pm 4.35$ points, respectively) were not significantly different from those 
Table 4 Comparison of PFS-R scores between two groups of patients before and after intervention $(\bar{x} \pm$ SD , \%)

\begin{tabular}{|c|c|c|c|c|c|}
\hline Dimensions & Time (Intervention) & Control group $(n=100)$ & Experimental group $(n=100)$ & Statistic ( $t$ value) & $P$ value \\
\hline \multirow{3}{*}{ Behavioral severity } & After & $5.83 \pm 1.22$ & $4.04 \pm 1.05$ & 11.121 & $<0.000$ \\
\hline & Statistic ( $t$ value) & 1.578 & 11.485 & & \\
\hline & $P$ value & 0.116 & $<0.000$ & & \\
\hline \multirow{3}{*}{ Affective meaning } & After & $6.11 \pm 1.09$ & $4.01 \pm 1.15$ & 13.253 & $<0.000$ \\
\hline & Statistic ( $t$ value) & 0.463 & 12.660 & & \\
\hline & $P$ value & 0.644 & $<0.000$ & & \\
\hline \multirow[t]{2}{*}{ Somatic sensation } & Before & $6.81 \pm 1.13$ & $6.56 \pm 1.08$ & 1.600 & 0.111 \\
\hline & $P$ value & 0.719 & $<0.000$ & & \\
\hline \multirow[t]{4}{*}{ Cognition/mood } & Before & $6.78 \pm 1.31$ & $6.49 \pm 1.18$ & 1.645 & 0.102 \\
\hline & After & $6.88 \pm 1.06$ & $5.21 \pm 1.12$ & 10.830 & $<0.000$ \\
\hline & Statistic ( $t$ value) & 0.593 & 7.868 & & \\
\hline & $P$ value & 0.554 & $<0.000$ & & \\
\hline
\end{tabular}

PFS-R, Revised Piper Fatigue Scale.

Table 5 Comparison of negative affect scale (SAS and SDS) scores between the two groups of patients before and after intervention ( $\bar{x} \pm$ SD, \%)

\begin{tabular}{|c|c|c|c|c|c|}
\hline Scale & Time (Intervention) & Control group $(n=100)$ & Experimental group $(n=100)$ & Statistic ( $t$ value) & $P$ value \\
\hline \multirow{3}{*}{ SAS } & After & $56.55 \pm 4.21$ & $44.42 \pm 3.64$ & 21.795 & $<0.000$ \\
\hline & Statistic ( $t$ value) & 0.224 & 24.947 & & \\
\hline & $P$ value & 0.823 & $<0.000$ & & \\
\hline \multirow{3}{*}{ SDS } & After & $55.12 \pm 4.35$ & $43.95 \pm 4.14$ & 18.601 & $<0.000$ \\
\hline & Statistic ( $t$ value) & 0.986 & 22.03 & & \\
\hline & $P$ value & 0.325 & $<0.000$ & & \\
\hline
\end{tabular}

SAS, Self-Rating Anxiety Scale; SDS, Self-rating Depression Scale.

before the intervention $(\mathrm{P}>0.05)$ (see Table 5).

\section{Discussion}

Colon cancer is a prevalent malignant tumor of the gastrointestinal tract, and the main treatment is a combination of surgery and chemotherapy (20). Colon cancer patients commonly experience negative emotions like anxiety and depression as they endure the physical pain caused by both the disease and the treatment process. These negative emotions can hinder the implementation of the treatment plan and reduce the patient's quality of life (21). The study found that AIT can effectively increase the level of psychological resilience for postoperative patients with 
colon cancer and reduce the degree of CRF and negative emotions.

\section{AIT is conducive to improving the psychological resilience of patients after colon cancer surgery}

The results of this study showed that the psychological resilience levels of the two groups before intervention were both relatively low. After the intervention, the CDRISC score of the experimental group was significantly higher than the pre-intervention score $(\mathrm{P}<0.05)$, while the score of the control group did not change significantly $(\mathrm{P}>0.05)$. This result suggests that AIT can effectively improve the psychological resilience of postoperative colon cancer patients, which is consistent with the results of similar studies in China and abroad $(22,23)$. AIT may improve the psychological resilience of patients after colon cancer surgery in several ways. First it can dislodge the patient's fixed assumptions and lead them to view problems more flexibly. Second, by learning a variety of new skills (forgiveness, acceptance and self-realization therapy, etc.), it can allow the patient to develop the ability to resolve inner struggles, and reduce the mental impact resulting from bodily trauma. Third, using gratitude as a foundation, AIT can eliminate negative emotions and stimulate positive emotions, thus relieving psychological pressure. Fourth, it can create warmth and ambience for the participants through group training and patient workshops. Overall, this approach encourages and enables the patient to understand himself or herself and change any inadequate behavior, thus strengthening confidence to defeat the disease. In the non-interventional control group, the participants instinctively focused on the disease itself, which compounds related stress, and increases the experience of negative emotions.

\section{AIT is helpful in reducing the degree of fatigue of patients after colon cancer surgery}

CRF is a complex syndrome caused by physical, psychological, emotional, and various other reasons. At present, there is no clear diagnostic standard or preferred treatment method (24). The results of this study showed that the PFS-R scores of the experimental group before intervention were not statistically different from those of the control group $(\mathrm{P}>0.05)$. After the intervention, the scores of CRF in the experimental group were significantly lower than those before intervention $(\mathrm{P}<0.05)$, while the scores in the control group did not change significantly $(\mathrm{P}>0.05)$. This result suggests that AIT is beneficial for reducing the fatigue of colon cancer patients postoperatively. It has been thought that lifestyle measures such as taking regular breaks and ensuring adequate sleep can help relieve CRF in cancer patients. AIT trains patients to practice transcendental meditation, and encourages participants' cultivation of self-care skills and dedication, so that they can establish an optimistic and healthy psychological state, thereby alleviating fatigue.

\section{AIT helps to reduce negative emotions in patients after colon cancer surgery}

The results of this study showed that the SAS and SDS scores of patients in the two groups before intervention both were high, indicating a state of depression and anxiety. After intervention, the scores of SAS and SDS in the experimental group were lower than those before intervention $(\mathrm{P}<0.05)$, while the scores of SAS and SDS in the control group did not significantly decrease $(\mathrm{P}>0.05)$. This result suggests that AIT beneficially reduces the anxiety and depression of postoperative patients with colon cancer, which is consistent with the results of Ye et al. (25). The rehabilitative mindfulness training of AIT can improve the participants focus, regulate the autonomic nervous system, and promote relaxation, which reduces emotional distress. Through the implementation of emotional diaries, We Chat, and video, patients can share cancer-related experiences, be supported by fellow participants, express their inner feelings, and vent negative emotions, thus effectively reducing the occurrence of anxiety and depression.

This study had some limitations, which includes a small sample size; a study with a larger sample size is needed for verification of the findings. Also, the research period was restricted to 10 weeks of intervention, and thus the effect of longer-term intervention is not clear, which necessitates further research using a longer study duration.

\section{Conclusions}

AIT can effectively improve the psychological resilience of patients after colon cancer surgery, relieve anxiety and depression, and reduce the degree of CRF.

The sample size of our research is not comprehensive enough to answer all relevant questions. In follow-up experiments, we will collect more patient data and will update the analysis results in another paper. 


\section{Acknowledgments}

We would like to thank the Affiliated Hospital of Jiangnan University for providing experimental equipment.

Funding: This work was supported by the Wuxi Municipal Health Committee (MS201924).

\section{Footnote}

Reporting Checklist: The authors have completed the CONSORT reporting checklist. Available at http://dx.doi. org/10.21037/apm-20-1370

Data Sharing Statement: Available at http://dx.doi. org/10.21037/apm-20-1370

Conflicts of Interest: All authors have completed the ICMJE uniform disclosure form (available at http://dx.doi. org/10.21037/apm-20-1370). The authors have no conflicts of interest to declare.

Ethical Statement: The authors are accountable for all aspects of the work in ensuring that questions related to the accuracy or integrity of any part of the work are appropriately investigated and resolved. This study was conducted in accordance with the ethical principles of the Declaration of Helsinki (as revised in 2013), and was approved by the Ethics Committee of the Affiliated Hospital of Jiangnan University [(2017) KY098]. Informed signed consent was given by all participants.

Open Access Statement: This is an Open Access article distributed in accordance with the Creative Commons Attribution-NonCommercial-NoDerivs 4.0 International License (CC BY-NC-ND 4.0), which permits the noncommercial replication and distribution of the article with the strict proviso that no changes or edits are made and the original work is properly cited (including links to both the formal publication through the relevant DOI and the license). See: https://creativecommons.org/licenses/by-nc-nd/4.0/.

\section{References}

1. Parkin DM, Pisani P, Ferlay J. Global cancer statistics. CA Cancer J Clin 1999;49:33-64, 1.

2. Kong L, Peng J, Li J, et al. Prolonged surveillance of colorectal cancer patients after curative surgeries beyond five years of follow-up. Ann Transl Med 2019;7:608.
3. Boyes AW, Girgis A, D'Este C, et al. Flourishing or floundering? Prevalence and correlates of anxiety and depression among a population-based sample of adult cancer survivors 6months after diagnosis. J Affect Disord 2011;135:184-92.

4. Han J, Liu J. Application progress of psychological group intervention in psychological adjustment of breast neoplasms patients. Chinese Journal of Nursing 2017;52:608-13.

5. Hong JF, Zhang W, Song YX, et al. Psychological distress among elderly patients with cancer. Chinese Journal of Nursing 2015;50:92-6.

6. Li G, Kong L, Zhou H, et al. Relationship between prenatal maternal stress and sleep quality in Chinese pregnant women: the mediation effect of resilience. Sleep Med 2016;25:8-12.

7. Reid R. Psychological Resilience. Med Leg J 2016;84:172-84.

8. Nowicki A, Piekarska J, Farbicka E. The assessment of cancer-related fatigue syndrome in patients with lung cancer during palliative chemotherapy. Adv Respir Med 2017;85:69-76.

9. Leak Bryant A, Walton AL, Phillips B. Cancer-related fatigue: scientific progress has been made in 40 years. Clin J Oncol Nurs 2015;19:137-9.

10. Chen HL, Liu K, You QS. Self-efficacy, cancer-related fatigue, and quality of life in patients with resected lung cancer. Eur J Cancer Care (Engl) 2018;27:e12934.

11. Loprinzi CE, Prasad K, Schroeder DR, et al. Stress Management and Resilience Training (SMART) program to decrease stress and enhance resilience among breast cancer survivors: a pilot randomized clinical trial. Clin Breast Cancer 2011;11:364-8.

12. Wu X'T, Zhang XQ, Wang QP, et al. Research progress of psychological resilience intervention in cancer patients. Chinese Journal of Nursing 2017;52:316-20.

13. Connor KM, Davidson JR. Development of a new resilience scale: the Connor-Davidson Resilience Scale (CD-RISC). Depress Anxiety 2003;18:76-82.

14. Chen YM, Yao H, Yan SY, et al. A study on effects of attention and interpretation therapy for patients with gastrointestinal cancer. Chinese Journal of Nursing 2020;2:250-6

15. Wu L, Tan Y, Liu Y. Factor structure and psychometric evaluation of the Connor-Davidson resilience scale in a new employee population of China. BMC Psychiatry 2017;17:49.

16. Annunziata MA, Muzzatti B, Mella S, et al. The revised 
piper fatigue scale (PFS-R) for Italian cancer patients: a validation study. Tumori 2010;96:276-81.

17. So WK, Dodgson J, Tai JW. Fatigue and quality of life among Chinese patients with hematologic malignancy after bone marrow transplantation. Cancer Nurs 2003;26:211-9.

18. Zung WW. A rating instrument for anxiety disorders. Psychosomatics 1971;12:371-9.

19. Nishina Y, Yoshioka SI. A Survey of Epilepsy-related Knowledge, Attitudes and Practices of Home Healthcare Nurses in the San-in Region of Japan. Yonago Acta Med 2018;61:19-26.

20. Tusaie K, Dyer J. Resilience: a historical review of the construct. Holist Nurs Pract 2004;18:3-8.

21. Hou WK, Lam JH. Resilience in the year after cancer diagnosis: a cross-lagged panel analysis of the reciprocity between psychological distress and well-being. J Behav Med 2014;37:391-401.

22. Steinhardt M, Dolbier C. Evaluation of a resilience

Cite this article as: Lin C, Diao Y, Dong Z, Song J, Bao C. The effect of attention and interpretation therapy on psychological resilience, cancer-related fatigue, and negative emotions of patients after colon cancer surgery. Ann Palliat Med 2020;9(5):3261-3270. doi: 10.21037/apm-20-1370 intervention to enhance coping strategies and protective factors and decrease symptomatology. J Am Coll Health 2008;56:445-53.

23. Bradshaw BG, Richardson GE, Kumpfer K, et al. Determining the efficacy of a resiliency training approach in adults with type 2 diabetes. Diabetes Educ 2007;33:650-9.

24. Pertl MM, Quigley J, Hevey D. 'I'm not complaining because I'm alive': barriers to the emergence of a discourse of cancer-related fatigue. Psychol Health 2014;29:141-61.

25. Ye ZJ, Liang MZ, Qiu HZ, et al. Effect of a multidiscipline mentor-based program, Be Resilient to Breast Cancer (BRBC), on female breast cancer survivors in mainland China-A randomized, controlled, theoretically-derived intervention trial. Breast Cancer Res Treat 2016;158:509-22.

(English Language Editors: J. Jones and J. Gray) 